\title{
Criteria for reporting incidental findings in clinical exome sequencing - a focus group study on professional practices and perspectives in Belgian genetic centres
}

\author{
Marlies Saelaert ${ }^{1 *}$, Heidi Mertes ${ }^{2}$, Tania Moerenhout ${ }^{1,3}$, Elfride De Baere ${ }^{4}$ and Ignaas Devisch ${ }^{1}$
}

\begin{abstract}
Background: Incidental and secondary findings (IFs and SFs) are subject to ongoing discussion as potential consequences of clinical exome sequencing (ES). International policy documents vary on the reporting of these findings. Discussion points include the practice of unintentionally identified IFs versus deliberately pursued SFs, patient opt-out possibilities and the spectrum of reportable findings. The heterogeneity of advice permits a nonstandardised disclosure but research is lacking on actual reporting practices. Therefore, this study assessed national reporting practices for IFs and SFs in clinical ES and the underlying professional perspectives.

Methods: A qualitative focus group study has been undertaken, including professionals from Belgian centres for medical genetics (CMGs). Data were analysed thematically.

Results: All Belgian CMGs participated in this study. Data analysis resulted in six main themes, including one regarding the reporting criteria used for IFs. All CMGs currently use ES-based panel testing. They have limited experience with IFs in clinical ES and are cautious about the pursuit of SFs. Two main reporting criteria for IFs were referred to by all CMGs: the clinical significance of the IF (including pathogenicity and medical actionability) and patient-related factors (including the patient's preference to know and patient characteristics). The consensus over the importance of these criteria contrasted with their challenging interpretation and application. Points of concern included IFs' pathogenicity in non-symptomatic persons, IFs concerning variants of uncertain significance, the requirement and definition of medical actionability and patient opt-out possibilities. Finally, reporting decisions were guided by the interaction between the clinical significance of the IF and patient characteristics. This interaction questions the possible disclosure of findings with context-dependent and personal utility, such as IFs concerning a carrier status. To evaluate the IF's final relevance, a professional and case-by-case deliberation was considered essential.

Conclusions: The challenging application of reporting criteria for IFs results in diversified practices and policy perspectives within Belgian CMGs. This echoes international concerns and may have consequences for effective policy recommendations,
\end{abstract}

Keywords: Incidental findings, Secondary findings, Clinical exome sequencing, Disclosure, Professional practice, Focus groups, Qualitative research

\footnotetext{
* Correspondence: Marlies.Saelaert@ugent.be

${ }^{1}$ Department of Public Health and Primary Care, Philosophy of Medicine and

Ethics Research Group, Ghent University, Campus Heymans (UZ Gent),

Corneel Heymanslaan 10 - Building 6K3, 9000 Ghent, Belgium

Full list of author information is available at the end of the article
}

(c) The Author(s). 2019 Open Access This article is distributed under the terms of the Creative Commons Attribution 4.0 International License (http://creativecommons.org/licenses/by/4.0/) which permits unrestricted use, distribution, and reproduction in any medium, provided you give appropriate credit to the original author(s) and the source, provide a link to the Creative Commons license, and indicate if changes were made. The Creative Commons Public Domain Dedication waiver (http://creativecommons.org/publicdomain/zero/1.0/) applies to the data made available in this article, unless otherwise stated. 


\section{Background}

Incidental findings (IFs) and secondary findings (SFs), which are variants in known disease genes unrelated to the diagnostic indication, are subject to ongoing discussion as potential consequences of clinical exome sequencing (ES) [1-3]. Since ES simultaneously covers all coding regions of a patient's genome, results unrelated to the diagnostic question can be found unintentionally, as IFs, or deliberately pursued, as SFs [2-5]. As ES is increasingly implemented for the diagnosis of monogenic diseases, various policy documents have been published regarding IFs and SFs in the US, Europe and Canada [1-3, 5-8]. However, these documents differ on fundamental issues and none of them is accepted as the general standard. Issues regarding (i) a practice of unintentional IFs versus actively pursued SFs, (ii) patient opt-out possibilities and (iii) the spectrum of reportable findings remain unresolved [9-11].

Firstly, the American College of Medical Genetics and Genomics (ACMG) has published highly influential recommendations which advocate the routine analysis of an additional panel of 59 genes and the reporting of all (likely) pathogenic variants when performing clinical ES $[2,3]$. Pathogenic (class 5) and likely pathogenic (class 4) variants can provide adequate grounds for altering a patient's surveillance or treatment [12]. Class 3 variants of uncertain significance (VUS), however, should not be considered as sufficient grounds for clinical decisionmaking [12]. Even though VUS might be reported when possibly relevant to the diagnostic question, their reporting is not advised when identified as IFs $[3,4,7,8]$. According to the ACMG, screening for (likely) pathogenic variants in the diagnostically unrelated gene panel should occur in every case of clinical exome and genome sequencing, as a realisation of the professional duty to avoid harm [2, 3, 10, 13]. However, this opportunistic screening has been criticised and the American Presidential Commission for the Study of Bioethical Issues (Bioethics Commission) notes how it might entail additional health risks, overwhelm patients with (ambivalent) information and stimulate a trend of medicalisation [5]. Therefore, the Bioethics Commission, and also EuroGentest, the European Society of Human Genetics (ESHG) and the Canadian College of Medical Geneticists (CCMG), are more cautious in their guidelines about reporting SFs and IFs $[1,5,7,8]$. They advocate a strictly necessary and proportional application of ES and, if possible, (exome or genome-based) targeted panel testing, which only analyses a subset of known disease-associated genes and hence minimises the possibility of diagnostically unrelated IFs $[1,4,7]$.

Secondly, the ACMG claims a patient's right to opt out of deliberately pursued SFs [13]. Taking into account all other international policy documents' advice of targeted testing and their restraint towards SFs, wide agreement on this opt-out possibility might be assumed $[1,7,8]$. International statements are more vague, however, about opting out of unintentional IFs. The Bioethics Commission, ESHG and Public Health Genetics (PHG) Foundation recommend that professionals should make a "prudent professional judgement" [5] concerning their fiduciary duty when a patient wants to opt out of an IF that is relevant, serious, and medically actionable (i.e. enabling surveillance and preventive and/or therapeutic interventions) [1, 3, 5, 14]. This way, a patient's right not to know might be overruled by a professional's presumed duty to avoid harm [3]. Recently published points to consider for laboratories, however, as well as the Canadian geneticists' position statement, strongly advocate respect for a patient's choice not to know IFs $[6,8]$.

Thirdly, the specific spectrum of genes or conditions that should be considered as reportable IFs or SFs, as well as the underlying reporting criteria, are strongly debated $[15,16]$. Lists of conditions and associated genes (including the ACMG gene list) have been challenged by the critique that variants might be classified differently or might be less penetrant and expressive in asymptomatic persons [15]. Hence the identification of IFs or SFs as predictive disease risks might be doubted [17]. Finally, the possibility of medical actionability has been stressed as an important criterion for reportable IFs and SFs in various recommendations $[1-3,5]$. Even though a semiquantitative metric has been developed as an attempt to assess medical actionability objectively, this criterion has been criticised [10, 18]. On the one hand, the mere availability of a medical intervention does not guarantee its effectiveness, and many interventions for conditions on the ACMG list are not supported in terms of their effectiveness by clinical trials or professional guidelines [14]. On the other hand, it has been suggested that the definition of medical actionability is too narrow and should also include reproductive choices or should be complemented by the criterion of personal utility (i.e. a personal interest or benefit that goes beyond improved healthcare outcomes) $[15,19]$.

Recently, the persistent lack of accord among policy documents has been exemplified in an international comparison of consent forms used for large gene panels, exome or genome sequencing. About half of the studied forms did not indicate their policy on reporting IFs or SFs and many used undefined terms (leaving the reference to IFs and/or SFs and corresponding reporting practices unclear) [20]. Moreover, the spectrum of reportable IFs and SFs (if specified) as well as the options to opt in for or opt out of (specific categories of) findings widely varied [20].

The diverse character of recommendations and consent forms and their inclusion of contested terms and criteria permits a non-standardised practice regarding IFs and SFs. However, only a limited amount of research has investigated the actual uptake of policy guidelines 
regarding IFs and SFs and has focussed on current reporting practices in a context of clinical ES. A USbased survey identified diverse practices regarding the spectrum of reportable IFs and SFs (which considerably exceeded the ACMG list) and different opt-in and optout possibilities [21]. Outside the US, two studies, each including laboratories from various countries, have analogously reported a variety in reported IFs [22, 23]. This study aims to further assess the actual practice regarding IFs and SFs in clinical ES, as well as to investigate the underlying professional perspectives. This research will also indicate which elements of international policy documents have been incorporated in practice as being most relevant or feasible and which elements demand further consideration or adjustment for efficient and successful policymaking.

\section{Methods}

\section{Recruitment and data collection}

To achieve an in-depth understanding of the practice and policy regarding IFs and SFs, a qualitative study was set up in Belgian centres for medical genetics (CMG). Belgium has eight CMGs: three in the Flemish Region, two in the Walloon Region and three in the BrusselsCapital Region. Since the aim was not to find out individual or role-specific views but the integrated perspective of each CMG, and to stimulate open conversation and interaction between colleagues, one focus group in every CMG was considered to be most appropriate [24]. A purposive sampling approach was used to recruit a multi-disciplinary and representative group of participants in every CMG, including both clinical and clinical laboratory geneticists and possibly other professionals. CMGs were informed about our study and its procedure by a presentation at the Belgian College of Medical Genetics (a federal body for quality of healthcare in medical genetics). Subsequently, a contact (usually the head of department) at each CMG was approached by email or telephone to request participation. If the contact agreed, they suggested a time which suited most of the CMG's professionals.

All focus groups were conducted in a room at the CMG or associated hospital between November 2016 and December 2017, and lasted between 67 and 117 $\mathrm{min}$. All focus groups were moderated by the first author and an observer was present and took field notes in seven out of eight focus groups. Focus groups were moderated in Dutch or English and participants could choose to speak Dutch, French or English.

A semi-structured interview guide, created after a thorough literature review, was evaluated by a multidisciplinary team of an ethicist (HM), geneticist (EDB) and philosopher (ID) and was used for all focus groups. Openended questions and probes to stimulate discussion were used (Table 1). Terminologically, "IF" was used to refer to unintentionally identified, diagnostically unrelated results. "SF" was used to refer to deliberately pursued, diagnostically unrelated findings. The study's specific focus on IFs and SFs in clinical ES for monogenic diseases, excluding preconception, prenatal, screening and research contexts, was emphasised at the outset of every focus group.

\section{Data analysis}

Focus groups were audio-recorded and transcribed verbatim and data are saved until completion of the full research project on a password-protected server. Data were analysed thematically, with an inductive approach and unrestricted by theoretical concepts. The analysis consisted of the consecutive stages of data immersion, code generation, theme identification, theme revision, theme definitions and production of the final report, as described by Braun and Clarke [25]. All data were coded by MS, and TM independently coded a substantial subset of the data. Analysis was an iterative and ongoing process during data collection. Text units could be included in more than one code and/or theme and the analysis was supported by use of a software program for qualitative data analysis (NVivo12). During analysis, ideas and reflections were stored as memos. An extensive procedure was developed to ensure the trustworthiness and credibility of the data collection, analysis and report. The procedure combined peer debriefing and a systematic audit trail, and covered both the process and the product of the analysis [26]. Following TM's secondary analysis of a data subset, the transcripts and initial code schemes were reviewed and theme names, definitions and structures were thoroughly discussed by MS and TM. Preliminary thematic structures and draft reports were discussed

\section{Table 1 Examples of interview questions}

How do you describe an IF in a clinical context in your CMG, apart from following guidelines? What terminology do you use?

What differences do you see between IFs in array testing and in clinical ES?

What kind of IFs do you report, firstly from the laboratory to the clinician, and secondly from the clinician to the patient?

What kind of policy regarding IFs would you like to create in the future? What impact do international guidelines on reporting IFs have on your own practice?

What difficulties do you experience in your practice regarding IFs or SFs?

What are the great challenges in the evolution of IFs?

What is your current practice regarding a patient's request to opt out of IFs?

How do you consider the intentional search for SFs?

What is your practice when new information is available about an IF, for example for recontacting patients?

Abbreviations used: CMG Centre for medical genetics, IF(s) Incidental finding(s), SF(s) Secondary finding(s), ES Exome sequencing. 
exhaustively and reviewed by the multidisciplinary group of authors until consensus was reached between all of them. Finally, quotes were selected and, if originally in Dutch or French, translated by MS and TM to illustrate the results. This article adheres to the COREQ guidelines for reporting qualitative research [27].

\section{Results}

All eight Belgian CMGs agreed to participate. Every focus group was composed multi-disciplinarily and involved between 6 and 11 participants, with a total number of 68 participating professionals (Table 2).

Six themes emerged from the data analysis: (i) current and general practice in clinical genetic testing, (ii) the position of genetics in medicine and society, (iii) criteria for reporting IFs, (iv) impact of IFs and SFs, (v) policy guidelines for genetic practice, (vi) guiding values and principles. This article addresses the third theme of the reporting criteria for IFs in a context of clinical ES in adults.

When considering the reporting of IFs, Belgian CMGs referred to two major criteria: the clinical significance of the IF and patient-related factors.

\section{Clinical significance of the IF}

Currently, Belgian CMGs do not analyse the full exome in clinical ES and mainly use exome-based panels, hitherto resulting in a rather limited experience with IFs in clinical ES. However, whole exome sequencing (WES) was identified as the undeniable future of clinical genetics. Due to the many monogenic conditions, IFs are expected to be frequent when very large panels or even the full exome will be analysed.

Professionals also referred to the possibility of screening additional genes as SFs when sequencing the exome, but a lack of (human, financial, and technical) resources and an unfulfilled need for guidelines (for example regarding reimbursement and the scope of analysis) fail to guarantee the required depth and trustworthiness of additional analyses in clinical WES. This could result in unnecessary interventions or harm and a false sense of security. Therefore, Belgian CMGs do not deliberately pursue SFs and only consider diagnostically unrelated findings in clinical ES when they are unintentionally identified as IFs (Table 3, Quote 1, Quote 2).

According to professionals in Belgian CMGs, reported IFs should be clinically significant, i.e. they should be relevant to a patient's health. CMGs especially referred to pathogenicity and medical actionability as important components of an IF's clinical significance. However, throughout the focus groups, the exact delineation of these criteria and their application in practice has turned out to be challenging.

\section{Pathogenicity}

A reported IF has to be a clinical risk factor, i.e. a variant predicted to cause disease, and various CMGs apply and advocated a cut-off for pathogenicity in reportable IFs. They suggested only reporting class 5 (pathogenic) and class 4 (likely pathogenic) variants in diagnostically unrelated but known disease genes. Class 3 variants (variants of uncertain significance or VUS), for example in an unrelated breast cancer gene, are not reported, as this might have a significant psychological impact or, as a consequence of unnecessary interventions, medically harmful consequences (Quote 3).

However, several factors complicate the definition of clearly pathogenic IFs. Firstly, verifying IFs' pathogenicity and predictive value in any particular patient is challenging in general, as there is usually no corresponding phenotype (i.e. patients are non-symptomatic for the IF's associated disease). Secondly, professionals described how, in the future, the advice not to report VUS in IFs might not always be realised. When a VUS is identified, it can be difficult to determine whether the affected gene is related to the symptomatic condition or not. CMGs noted that a VUS in a diagnostically relevant gene is sometimes reported, but when the gene's diagnostic relevance is not fully guaranteed, this reporting might undermine the cut-off for pathogenicity in IFs. Thirdly, variant classifications are dynamic and a VUS may be reclassified as a pathogenic variant over time. When this variant turns out to be relevant to the symptomatic condition, its reclassification may eventually lead to a diagnosis, which patients usually experience as a relief. Therefore, professionals acknowledged the duty to recontact patients

Table 2 Focus group participants

\begin{tabular}{lccccccccc}
\hline & FG1 & FG2 & FG3 & FG4 & FG5 & FG6 & FG7 & FG8 & Total \\
\hline Participant's profession & & & & & & & & & \\
$\quad$ Clinical geneticist & 3 & 3 & 4 & 5 & 3 & 3 & 2 & 2 & 25 \\
$\quad$ Clinical laboratory geneticist & 3 & 3 & 4 & 2 & 4 & 2 & 2 & 6 & 26 \\
Genetic counsellor/Psychologist & & 4 & 1 & 2 & 1 & 1 & 2 & 11 \\
$\quad$ Other (Bio-informatician, Bioethicist, Trainee MD) & & 1 & & 1 & & & 3 & 1 & 6 \\
Total & 6 & 11 & 9 & 10 & 8 & 6 & 9 & 9 \\
\hline
\end{tabular}

Abbreviations used: FG Focus group. 
Table 3 Quotes

\begin{tabular}{|c|c|c|}
\hline Number & Quote & Participant \\
\hline Quote 1 & $\begin{array}{l}\text { "Maybe, at random, we could find something and when we find something that we are sure of, we will } \\
\text { tell you. [... ] But we won't actively look for it." }\end{array}$ & $\begin{array}{l}\text { FG } 8 \text { - P9 Clinical laboratory } \\
\text { geneticist }\end{array}$ \\
\hline Quote 2 & $\begin{array}{l}\text { "There is a filter in accordance with the ACMG recommendations, but it is not used as standard. [ ... ] It } \\
\text { takes considerable human capacity to analyse those things and currently it is not included in our } \\
\text { routine-protocol, to look at those things as standard." }\end{array}$ & $\begin{array}{l}\text { FG } 7 \text { - P7 Clinical laboratory } \\
\text { geneticist }\end{array}$ \\
\hline Quote 3 & $\begin{array}{l}\text { "The reporting of variants where even we don't know whether they mean anything, is the equivalent to } \\
\text { reporting non-information which might make a patient despair or ask for an impossible follow-up. [... ] } \\
\text { So I think we have a responsibility as professionals not to go that far." }\end{array}$ & $\begin{array}{l}\text { FG } 2 \text { - P10 Clinical laboratory } \\
\text { geneticist }\end{array}$ \\
\hline Quote 4 & $\begin{array}{l}\text { A: "The example would be, in theory, because now we wouldn't see it, eh, Huntington's disease, if you } \\
\text { see that, at whatever age, should you transmit [report] it? So far, the answer is no. [... ] And any other } \\
\text { change for which you have nothing to offer to the patient, we don't report." [...] } \\
\text { B: "But you can have Parkinson's, Alzheimer's ... with a point mutation, for example." } \\
\text { A: }\end{array}$ & $\begin{array}{l}\text { FG } 1 \mathrm{~A}=\mathrm{P} 5 \text {, Clinical geneticist } \\
\mathrm{B}=\mathrm{P} 1 \text {, Clinical geneticist }\end{array}$ \\
\hline Quote 5 & $\begin{array}{l}\text { "[... ] and then, during the next pregnancy, they would find out that their child has Duchenne... You } \\
\text { don't want to have this [kind of situation], whereas we have seen it during a previous [test], for example } \\
\text { in their daughter. So currently, we don't work with an opt-out, to avoid this kind of thing. And l've never } \\
\text { met a family who had problems with this [practice]." }\end{array}$ & FG 2 - P2 Clinical geneticist \\
\hline Quote 6 & $\begin{array}{l}\text { "[... ] so people have to decide between opt-in and opt-out, and I think it is very complex for people to } \\
\text { be sufficiently informed about this choice. [... I It's hopeless, people can't choose, well, most of them } \\
\text { can't. I mean, most people don't have any background knowledge of genetics, so it is extremely difficult." }\end{array}$ & FG 4 - P7 Psychologist \\
\hline Quote 7 & $\begin{array}{l}\text { "A possibility to choose ... You cannot simply force someone, I mean, you can't just ... The aim of } \\
\text { informed consent is to make a deliberate choice, so you have to give people the right information, so } \\
\text { they can make a choice. I think that is the aim of informed consent." }\end{array}$ & FG 6 - P1 Genetic counsellor \\
\hline \multirow[t]{2}{*}{ Quote 8} & $\begin{array}{l}\text { A: "But, perhaps I don't understand, if the patient chooses [an] opt-out, then we don't report. [... ] If the } \\
\text { patient chooses, and it's clear, to opt out, then we don't report." }\end{array}$ & FG $3 \mathrm{~A}=\mathrm{P} 1$, Clinical geneticist \\
\hline & $\begin{array}{l}\text { B: "But I would anyway! [... ] I would say, the consequence of not reporting and maybe losing a parent, } \\
\text { for example the [patient's] mother very, very young ... Those consequences are so important that I } \\
\text { would choose to disregard the patient's decision, I would note it down in the file that I choose to } \\
\text { disregard, because [... ] I consider the consequence of not reporting to be worse than the consequences } \\
\text { of reporting." }\end{array}$ & $\mathrm{B}=\mathrm{P} 8$, Clinical geneticist \\
\hline Quote 9 & $\begin{array}{l}\text { "So generally, when we have an IF like that, most of the time there is a deliberation between the } \\
\text { biologist [clinical laboratory geneticist] who is responsible for the analysis and the clinician [clinical } \\
\text { geneticist] who validates the test. [... ] Sometimes, we even call upon external people, other centres, or } \\
\text { people who have the right experience." }\end{array}$ & FG 5 - P5 Clinical geneticist \\
\hline
\end{tabular}

Abbreviations used: FG Focus group, P Participant, IF(s) Incidental finding(s), ACMG American College of Medical Genetics and Genomics

regarding the reinterpretation of diagnostic results. In the context of IFs, however, recontacting patients regarding a reclassified VUS, was regarded as logistically impossible. Moreover, professionals suggested that such a delayed report of an IF would only be appropriate if patients explicitly agreed to it, as this finding is not directly related to the indication for testing and does not realise the pursued diagnosis.

\section{Medical actionability}

Most CMGs exclusively report actionable IFs, which were described as findings for which medical therapy, treatment or preventive screening are available (Quote 4). Several professionals regarded the knowledge of IFs ad infinitum, including non-actionable IFs, as harmful, because this includes information that patients do not understand and cannot handle (practically or psychologically). Professionals also expressed feeling powerless themselves about non-actionable IFs and feeling "more comfortable with a cancer predisposition than with [a predisposition for] a neuro-degenerative condition". These professionals considered the limitation of reportable IFs to actionable results as a consequence of their professional duty and responsibility to decide on relevant information. Ultimately, only reporting actionable IFs was presented as a pragmatic way of keeping clinical ES practically feasible, as excluding non-actionable findings reduces the time required for analysis.

Even though they had not actually been in this situation, some professionals remarked that not reporting non-actionable IFs, for example regarding a neuro-degenerative condition, could be an ethically difficult decision, as it would withhold important information from patients and/ or their families. Therefore, one CMG explicitly stated that if they identified serious, non-actionable IFs, these would be reported. Another CMG suggested that non-actionable results might, depending on the specific circumstances, be reported as IFs, but, if a practice for SFs were developed, these deliberately pursued results should only concern medically actionable findings. 
The use of a standard list of medically actionable genes was proposed. Many Belgian CMGs use the ACMG list of "highly penetrant and actionable genes" as a (not strictly binding) framework for reportable IFs [2, 3]. On the other hand, some CMGs considered such a list as being in conflict with the dynamic reality of treatments and preventions that can become available over time. Hence a variant's actionability might better be determined at the time of discovery.

Finally, a correlation was suggested between a condition's actionability and penetrance. Even though risks are subjectively interpreted, "low penetrance" IFs were considered to be too abstract, and classifying them as actionable might create unrealistic expectations regarding the utility of this information. Therefore, as a suggestion for future policy, actionable IFs should be highly penetrant and patients should be counselled in interpreting incomplete penetrance.

\section{Patient-related factors}

As a second criterion for reporting IFs, CMGs referred to patient-related factors, being the patient's preference to know IFs and patient characteristics.

\section{Preference to know}

ES allows a selection of analysed genes and hence, theoretically, a choice to receive IFs or not. However, not all Belgian CMGs offer this opportunity, and practices on a patient opt-in and opt-out vary widely.

Three CMGs currently offer no opt-out of actionable IFs, although one of them offers an opt-out of non-actionable IFs. Professionals at these CMGs argued firstly that they have the ambition or even the duty to prevent future disease that can be avoided (Quote 5) and secondly that lay people do not truly understand the meaning and possible impact of IFs. In the event of an optout, patients would not realise what they are actually declining (Quote 6). As a third argument, two CMGs mentioned their ethics committee's influence on this policy. It did not allow an opt-out of actionable IFs because professionals should report useful information when it is available and, again, because patients would not understand their own decision. Finally, it was observed that patients generally do not dispute the possibility of receiving actionable IFs. One CMG added that, even if an opt-out is not suggested, patients can spontaneously ask for it, but no such cases were mentioned during the focus group.

Despite these arguments, one CMG explicitly discussed its current policy and reported an exception by honouring a patient's request not to look at breast cancer genes during an unrelated clinical ES. Two centres mentioned that it would be good to update their ethics committee on recent developments in clinical ES, possibly to re-evaluate their opt-out policy. Finally, it was recognised that patients might be distressed when discovering future health risks as IFs. Nonetheless, these worries were said to be inevitable, as the risk would probably manifest itself anyway at a later point in life.

Conversely, four CMGs always allow an opt-out of actionable IFs. To justify their policy, these CMGs also referred to the idea that IFs might be complex to comprehend, also in psychological terms. Some patients might not be able to deal with the information, and therefore their preference to opt out of these results should be respected. Moreover, these CMGs stated that patients' general and fundamental right not to know should be honoured (Quote 7). Nevertheless, it was mentioned that only a small minority of patients actually choose to opt out of actionable IFs.

Finally, one CMG, with limited experience with clinical ES, discussed its future policy and the possibility of an opt-out in depth. While some of its professionals strongly defended absolute respect for a patient's choice, one participant claimed that opting out should only be accepted if it has minor implications for the patient's prognosis. When not reporting actionable IFs could have severe consequences, this professional would overrule a patient's opt-out. Again it was argued that patients do not understand what IFs and an opt-out really mean. Moreover, the possible harm of not reporting an actionable IF would outweigh the harm of being informed against one's will (Quote 8). To reconcile the two perspectives in this CMG, two opposing solutions were suggested for a patient's optout: the IF could be reported at a later and more suitable moment, or the IF could be masked in the report from the laboratory to the clinician. That way, situations where the clinician knows but cannot disclose relevant patient information could be avoided.

\section{Patient characteristics}

Finally, professionals noted that patient characteristics influence whether and how an IF is reported, as patients' (clinical and personal) context interacts with the IF's clinical significance and affects its final relevance. Professionals provided the hypothetical example of the importance of a patient's primary condition for the timing of reporting an IF as well as for the suggested follow-up and counselling, since both results are considered to have an integrated impact on a patient's health and life. A patient's wish for future children or his/her family history of illness might also affect the disclosure of an IF regarding a carrier status or of a non-actionable IF (since it could explain an undiagnosed family condition). These last examples illustrated how personal and family characteristics interact with the definition of actionability and hence might affect an IF's clinical significance and disclosure. Most CMGs did not consider actionability to 
include lifestyle adjustments or personally useful actions. However, they did discuss actionability in terms of reproductive decision making, which would enable the reporting of IFs concerning a carrier status for a recessive condition. Some professionals do or would not report these findings, because they are not clinically threatening for patients themselves. It was also mentioned that including prenatal possibilities "would make every condition actionable". However, and depending on personal and/or family characteristics and plans, these results can be relevant to relatives and (future) children. Therefore, half of the CMGs would consider the reporting of IFs regarding a carrier status for severe diseases (for example cystic fibrosis or Duchenne muscular dystrophy). Two centres already reported such findings and one does not offer an opt-out of them. Nonetheless, the psychological impact of this disclosure was acknowledged and one CMG testified about a family that was emotionally upset by the disclosure of a cystic fibrosis carrier status.

The interaction between, on the one hand, a patient's characteristics and (clinical, personal, reproductive, family, etc.) context and, on the other hand, the clinical significance (including the actionability) of IFs does not result in a standard outcome, and hence evaluating an IF's final relevance frequently requires a professional, multidisciplinary deliberation (Quote 9). To facilitate the deliberation process, a national (online) consortium on IFs was suggested, where "difficult cases" could be discussed, as well as a specialist committee to relieve CMGs of the exclusive responsibility regarding disclosure.

Despite the case-by-case deliberation, some professionals would still prefer general guidelines, for example regarding pathogenic variants and actionability, to facilitate the professional decision about disclosure.

\section{Discussion}

An analysis of current practice at Belgian CMGs regarding clinical ES in the context of adult testing revealed a diagnostic focus and a standard procedure of exomebased panel testing, resulting in a low incidence of IFs. Belgian CMGs' collective policy not to deliberately pursue SFs mirrors the avoidance of diagnostically unrelated findings and accords with current laboratory practices and with all international guidelines apart from the ACMG recommendations [1-3, 6-8, 23, 28].

Whether CMGs report an IF is determined by an interaction between the clinical significance of the IF and patient-related factors.

\section{Clinical significance of the IF}

Belgian professionals indicated pathogenicity and medical actionability as important components of an IF's clinical significance. These criteria are not surprising in themselves, as they are also stressed by leading American and European recommendations [1-3, 7]. Nonetheless, these criteria were extensively discussed because their interpretation and application in practice turns out to be challenging.

The importance of IFs' pathogenicity was unanimously emphasised. However, Belgian CMGs also expressed concerns about IFs' disease predictive value in asymptomatic persons. This idea is echoed internationally, even by the ACMG itself [3, 6, 9, 29, 30]. Richards et al. mentioned that variants might be less pathogenic and less penetrant if they are unrelated to the primary test indication and when there is no phenotype or family history of the associated condition [12]. The caution with which Belgian professionals approach the pathogenicity of IFs reflects these remarks, as well as the warning that unreliably interpreted and reported results might cause physical and psychological harm [15, 31]. The parallel idea expressed by Belgian CMGs regarding a cut-off for pathogenicity in IFs, and the suggestion to only report class 5 and class 4 but not class 3 variants (VUS), accords with international laboratory practices and points to consider, and with the ACMG recommendations $[2-4,6,21]$. Not reporting VUS in IFs from the laboratory to the ordering clinician prevents an over-interpretation of these results' significance for the diagnostic question and needless patient follow-up [6, 23, 32].

Along with pathogenicity, most but not all CMGs assessed an additional threshold for reportable IFs, being their actionability. This criterion, as well as its interpretation as medical actionability, corresponds with an international consensus and might be partly explained by professionals' specific role as medical experts [1, 3, 5, 11, 28-30,33]. Nonetheless, the exclusive reporting of actionable IFs was characterised as a dynamic and ethically difficult policy by some Belgian centres. Some CMGs suggested to identify low penetrance IFs as non-actionable, which refers to a correlation between criteria that has already been indicated by the ACMG and its current list of 59 "highly penetrant and actionable genes" that should be analysed as SFs [2, 3]. Conversely, it has also been suggested that variants' low penetrance can be countered by the associated condition's actionability $[28,30]$.

\section{Patient-related factors}

A notable finding of this study is Belgium's diverse practice regarding the opt-out of actionable IFs. The absence of the possibility to opt out was legitimised by the professional aim to avoid harm. However, in-house discussions about this mandatory opt-in policy and professional concerns about the psychological impact of reported IFs illustrated that the superiority of professional duty over a patient's choice is not self-evident. This value conflict was most visible in one CMG's consideration of overruling a 
patient's choice to opt out when it was considered to have harmful consequences. The denial of a patient's preference, granting this criterion only a relative weight, sounds polemical but is in line with the "prudent professional judgement" which is advocated by bodies including the ESHG and Bioethics Commission $[1,5]$. It also reflects the idea that the denial of a patient's choice is sometimes inevitable, for example when a patient opts out of clinically relevant or medically actionable IFs $[9,16,31]$. The second argument for the obligatory disclosure of actionable IFs, being patients' presumed inability to fully understand their impact, has also been suggested internationally $[9,32]$. However, postulating a patient's inability to make well-informed decisions might discount the efficacy of counselling procedures $[5,8,34]$.

Patients' general acceptance of disclosing actionable IFs supports the consolidation of offering no opt-out. However, an absence of questions might not necessarily equal an omnipresent preference to actually know IFs. When a CMG does not suggest an opt-out, few patients might have the genetic literacy to ask for one spontaneously, since the public understanding of genetics and its possibilities seems to be rather limited [35]. Moreover, it takes courage to dispute the professional authority of an informed consent form or pre-test counselling, or to resist the societal pressure to know as much as possible [33, 36]. Finally, a Belgian CMG's claim that an IF, and the corresponding psychological distress, will manifest itself anyway at a later time might not be completely valid, as the incidentally identified variant could have an incomplete penetrance and/or variable expression, an idea related to the uncertain pathogenicity of IFs in asymptomatic persons.

Belgian CMGs that allow an opt-out of actionable IFs emphasise the honouring of patients' wishes and their right not to know. This conflicts with well-known European recommendations but accords with a Canadian position statement and recent points to consider, and it is supported by international professional preferences $[6,8,30,37]$. The Belgian suggestion that results should be masked in the laboratory report for the clinician when patients opt out, has been expressed internationally [31]. However, problems might arise when, as a result of changed circumstances or values, patients change their mind and do want to know IFs [16].

Finally, there is a general agreement, both within Belgian CMGs and internationally, that the interaction between an IF's clinical significance and patient characteristics affects the final relevance of an IF $[9,15,16,23,30,32,33]$. This interaction clearly shows in the impact of a patient's personal context on the criterion and definition of IFs' actionability and, more particularly, in the relevance and possible disclosure of IFs regarding a carrier status. Both within Belgian CMGs and internationally, this possible reporting is strongly discussed, as it might enable reproductive and/or (future) family-wide choices and actions [9, 23, 30,33]. Even though reporting a carrier status for recessive conditions is in conflict with Belgian CMGs' general focus on direct, medical actionability, half of them would favour such reporting to adults. This disclosure is supported by international professionals' preferences and recent laboratory points to consider $[6,16,21,23]$. On the other hand, it conflicts with the ACMG recommendations and creates an additional workload for results which are not clinically significant for patients themselves [2, 3, 16, 23]. However, this claim of reduced significance is countered by the impact of a reported carrier status on a person's selfconcept and specifically by the way it might threaten a person's genetic identity, (future) health perception or wished-for parental role [38, 39], a psychological effect which was also insinuated by two Belgian CMGs. The impact of knowing one's carrier status might even be more substantial in the case of a serious X-linked condition, such as fragile $\mathrm{X}$ syndrome, where carrying the premutation might also have clinical consequences for the carrier herself [40]. Belgian professionals did not raise this specific example of an IF regarding a carrier status, but nonetheless it goes against their statement that such a finding is non-threatening for patients themselves.

The reporting of IFs regarding a carrier status because of its possible value in the specific (personal or family) context of reproduction, can be considered in the more general debate on personal utility [19]. The concept of personal utility might, based on a patient's characteristics and context, categorise findings which allow future (reproductive) choices, psychological or social coping or intrinsically valuable self-knowledge as reportable results, as they enable non-medical but valuable actions $[19,41]$. Even though CMGs acknowledge the importance of a patient's context and the difficulty of not reporting medically non-actionable IFs, most CMGs are not likely to add these options of personal utility to the actionability-criterion. Moreover, personal utility risks becoming an unspecified umbrella term that justifies the reporting of any kind of results [19, 42]. Therefore, Bunnik et al. suggest limiting personal utility to meaningful, technically and clinically valid information which "can reasonably be used for decisions, actions or self-understanding" [42]. As a consequence of its problematic definition, Vears et al. even suggest not assessing actionability as a decisive criterion for reporting pathogenically significant IFs [6].

As a second consequence of the interaction between an IF's clinical significance and patient characteristics, the value of professional deliberation is stressed by both Belgian and international professionals [9, 11, 16, 23]. On the other hand, some CMGs' call for guidelines on 
pathogenicity or actionability is also mirrored in international research, for example, concerning clinical laboratory geneticists who favour a list of conditions and genes that should be considered $[9,11,15,23,29]$.

The tension between a call for (more) guidelines and a patient-specific, case-by-case deliberation has been identified previously [23]. As ES is increasingly implemented in clinical practice, it seems advisable, at least at a local level of CMGs, to create a guiding framework which is clarified to patients before testing and which relieves professionals from the responsibility to individually decide on every case of IFs. To further avoid the chance and injustice of offering different information to different patients, not only within but also between CMGs, an (inter)national consensus on relevant criteria might be pursued as a starting point for reporting practices $[20,22,23,43]$. However, if general guidelines turn out to be unfeasible and the current diversity in national practice, as disclosed by this study, and in international practice and policy documents is maintained, a patient's informed decision on which results to receive, starts with his/her choice of a specific CMG. In that case, it is quintessential for every CMG to disclose its local policy. On the other hand, and in line with the non-standardised outcome of the interaction between the clinical significance of IFs and patient characteristics, a flexibility in guidelines' application has been advocated so they can be accustomed to the particular context [44]. Together with the professional expertise in CMGs, this call for a personalised deliberation nuances the need for and effectiveness of a rigid "one model fits all" policy [23]. Therefore, the contextualised application of a guiding framework of reporting criteria for IFs, might result in a personalised, non-standardised outcome.

To our knowledge, this is the first study on reporting practices and criteria regarding IFs which includes nationwide certified CMGs and hence achieves a good coverage of a national, non-commercial practice. The organization of one focus group in every centre revealed the similarities and differences in practice between centres. Moreover, it encouraged an open discussion between colleagues and a clarification of underlying reporting criteria. These results emerged from a Belgian context, with its specific scale and healthcare organisation. Nonetheless, the results of this study might be (partly) transferrable to other (and larger) countries with similar healthcare systems and analogous confrontations with diverse international guidelines, but further research is needed to confirm or deny similarities in practice and policy. As a consequence of Belgian CMGs' standard practice of diagnostic exome-based panel testing, there is still a limited experience with actual IFs in clinical ES. Consequently, the perspectives expressed by the CMGs might reflect current reporting practices as well as preferable future policies. Future research should identify whether these perspectives are actually effected when the exome is fully analysed in clinical practice and IFs become more frequent.

\section{Conclusions}

Belgian CMGs agree in their reference to common and internationally suggested reporting criteria for IFs. However, these criteria resist a uniform interpretation and hence result in a diversified Belgian practice, which reflects divergent, international policy perspectives. Belgian CMGs consent to the threshold of pathogenicity but concerns about IFs' predictive value in non-symptomatic persons and VUS in IFs challenge this criterion's application in practice. Furthermore, (medical) actionability is both an advocated and contested threshold, both internationally and at Belgian CMGs. In their adherence to international perspectives, Belgian CMGs differ most manifestly regarding patient optout possibilities for actionable IFs and in the weighing of professional duty versus patient autonomy. Finally, the interaction between the clinical significance of IFs and patient characteristics questions the definition of actionability and the possible reporting of IFs with personal utility such as findings concerning a carrier status. The importance of the patient's context and the non-standardised outcome of its interaction with IFs' clinical significance suggest the imminent inclusion of case-by-case reflections in reporting decisions. Accordingly, (international) guidelines for the reporting of IFs in clinical ES might only be effective when they are sufficiently detailed in terms of the criteria applied as well as responsive to the particularity of each individual case.

\section{Abbreviations \\ ACMG: American College of Medical Genetics and Genomics; Bioethics Commission: American Presidential Commission for the Study of Bioethical Issues; CCMG: Canadian College of Medical Geneticists; CMG(s): Centre(s) for medical genetics; ES: Exome sequencing; ESHG: European Society of Human Genetics; FG: Focus group; IF(s): Incidental finding(s); P: Participant; PHG Foundation: Public Health Genetics Foundation; SF(s): Secondary finding(s); VUS: Variant(s) of uncertain significance; WES: Whole exome sequencing}

\section{Acknowledgements \\ We would like to thank all professionals from the included CMGs for their participation.}

\section{Authors' contributions}

MS developed the interview guide, recruited the participants, moderated, transcribed and thematically analysed the focus groups and was a major contributor in writing the manuscript. HM evaluated the interview guide, attended the focus groups as an observer, evaluated thematic structures and fundamentally reviewed draft manuscripts. TM made a secondary analysis of a data subset, including transcripts and initial code schemes, and revised and discussed theme names, definitions and structures with MS until consensus was reached. TM also fundamentally reviewed draft manuscripts. EDB and ID facilitated recruitment and evaluated the interview guide and preliminary thematic structures. EDB and ID exhaustively reviewed draft manuscripts and contributed to the final structure. All authors have read and approved the final manuscript. 


\section{Funding}

This study is supported by a Special Research Fund - Concerted Research Actions (BOF - GOA) BOF15/GOA/011. Co-authors HM and EDB are supported by funding from the Research Foundation Flanders - Fonds Wetenschappelijk Onderzoek (FWO), respectively $1205415 \mathrm{~N}$ and $1802215 \mathrm{~N}$. Co-author TM is supported by a Clinical PhD fellowship from the Research Foundation Flanders - Fonds Wetenschappelijk Onderzoek (FWO), $1700618 \mathrm{~N}$

The funding sources had no role in the design and conduct of the study, in the collection, management, analysis and interpretation of the data, or in the preparation, review, or approval of the manuscript.

\section{Availability of data and materials}

None of the data generated and analysed during this study are publically available for reasons of personal privacy, but they are available from the corresponding author in response to a reasonable request.

\section{Ethics approval and consent to participate}

This study is approved by the Commission of Medical Ethics at Ghent University Hospital (reference number B670201628974). Participants signed an informed consent form, and personal information was altered or removed to create an anonymous report.

\section{Consent for publication}

All participants signed an informed consent form which included a statement on the anonymised publication of study results.

\section{Competing interests}

The authors declare that they have no competing interests.

\section{Author details}

${ }^{1}$ Department of Public Health and Primary Care, Philosophy of Medicine and Ethics Research Group, Ghent University, Campus Heymans (UZ Gent), Corneel Heymanslaan 10 - Building 6K3, 9000 Ghent, Belgium. ${ }^{2}$ Department of Philosophy and Moral Sciences, Bioethics Institute Ghent, Ghent University, Ghent, Belgium. ${ }^{3}$ Department of Philosophy and Moral Sciences, Ghent University, Ghent, Belgium. ${ }^{4}$ Center for Medical Genetics Ghent (CMGG), Ghent University and Ghent University Hospital, Ghent, Belgium.

Received: 12 July 2019 Accepted: 24 July 2019

Published online: 20 August 2019

\section{References}

1. van El CG, Cornel MC, Borry P, Hastings RJ, Fellmann F, Hodgson SV, et al. Whole-genome sequencing in health care recommendations of the European Society of Human Genetics. Eur J Hum Genet. 2013;21(6):580-4.

2. Kalia SS, Adelman K, Bale SJ, Chung WK, Eng C, Evans JP, et al. Recommendations for reporting of secondary findings in clinical exome and genome sequencing, 2016 update (ACMG SF v2.0): a policy statement of the American College of Medical Genetics and Genomics. Genet Med. 2017;19(2):249-55

3. Green RC, Berg JS, Grody WW, Kalia SS, Korf BR, Martin CL, et al. ACMG recommendations for reporting of incidental findings in clinical exome and genome sequencing. Genet Med. 2013;15(7):565-74.

4. Rehm HL, Bale SJ, Bayrak-Toydemir P, Berg JS, Brown KK, Deignan JL, et al. ACMG clinical laboratory standards for next-generation sequencing. Genet Med. 2013;15(9):733.

5. Anticipate and communicate: ethical management of incidental and secondary findings in the clinical, research, and direct-to-consumer contexts. 2013. http://bioethics.gov/sites/default/files/ FINALAnticipateCommunicate_PCSBI_0.pdf. Accessed June 2017.

6. Vears $D$, Sénécal $K$, Clarke A, Jackson L, Laberge A, Lovrecic L, et al. Points to consider for laboratories reporting results from diagnostic genomic sequencing. Eur J Hum Genet. 2018;26(1):36.

7. Matthijs G, Souche E, Alders M, Corveleyn A, Eck S, Feenstra I, et al. Guidelines for diagnostic next-generation sequencing. Eur J Hum Genet. 2016;24(1):2-5.

8. Boycott K, Hartley T, Adam S, Bernier F, Chong K, Fernandez BA, et al. The clinical application of genome-wide sequencing for monogenic diseases in Canada: position statement of the Canadian College of Medical Geneticists. J Med Genet. 2015;52(7):431-7.
9. Mackley MP, Fletcher B, Parker M, Watkins H, Ormondroyd E. Stakeholder views on secondary findings in whole-genome and whole-exome sequencing: a systematic review of quantitative and qualitative studies. Genet Med. 2017;19(3):283-93.

10. Ormond KE, O'Daniel JM, Kalia SS. Secondary findings: how did we get here, and where are we going? J Genet Couns. 2019;28(2):326-33.

11. Gourna EG, Armstrong N, Wallace SE. Compare and contrast: a cross-national study across UK, USA and Greek experts regarding return of incidental findings from clinical sequencing. Eur J Hum Genet. 2016;24(3):344-9.

12. Richards S, Aziz N, Bale S, Bick D, Das S, Gastier-Foster J, et al. Standards and guidelines for the interpretation of sequence variants: a joint consensus recommendation of the American College of Medical Genetics and Genomics and the Association for Molecular Pathology. Genet Med. 2015; 17(5):405-24.

13. ACMG Board of Directors. ACMG policy statement: updated recommendations regarding analysis and reporting of secondary findings in clinical genome-scale sequencing. Genet Med. 2015;17:68-9.

14. Richer J, Laberge AM. Secondary findings from next-generation sequencing: what does actionable in childhood really mean? Genet Med. 2019;21(1):124-32.

15. Ormondroyd E, Mackley MP, Blair E, Craft J, Knight JC, Taylor JC, et al. "not pathogenic until proven otherwise": perspectives of UK clinical genomics professionals toward secondary findings in context of a genomic medicine multidisciplinary team and the 100,000 genomes project. Genet Med. 2018; 20(3):320-8.

16. Grove ME, Wolpert MN, Cho MK, Lee SSJ, Ormond KE. Views of genetics health professionals on the return of genomic results. J Genet Couns. 2014:23(4):531-8.

17. Holtzman NA. ACMG recommendations on incidental findings are flawed scientifically and ethically. Genet Med. 2013;15(9):750-1.

18. Berg JS, Foreman AKM, O'Daniel JM, Booker JK, Boshe L, Carey T, et al. A semiquantitative metric for evaluating clinical actionability of incidental or secondary findings from genome-scale sequencing. Genet Med. 2016:18(5):467-75

19. Urban A, Schweda M. Clinical and personal utility of genomic highthroughput technologies: perspectives of medical professionals and affected persons. New Genet Soc. 2018;37(2):153-73.

20. Vears DF, Niemiec E, Howard HC, Borry P. How do consent forms for diagnostic high-throughput sequencing address unsolicited and secondary findings? A content analysis. Clin Genet. 2018;94(3-4):321-9.

21. O'Daniel JM, McLaughlin HM, Amendola LM, Bale SJ, Berg JS, Bick D, et al. A survey of current practices for genomic sequencing test interpretation and reporting processes in US laboratories. Genet Med. 2017;19(5):575-82.

22. Hehir-Kwa JY, Claustres M, Hastings RJ, van Ravenswaaij-Arts C, Christenhusz G, Genuardi M, et al. Towards a European consensus for reporting incidental findings during clinical NGS testing. Eur J Hum Genet. 2015;23(12):1601-6.

23. Vears DF, Senecal K, Borry P. Reporting practices for unsolicited and secondary findings from next-generation sequencing technologies: perspectives of laboratory personnel. Hum Mutat. 2017:38(8):905-11.

24. Gill P, Stewart K, Treasure E, Chadwick B. Methods of data collection in qualitative research: interviews and focus groups. Br Dent J. 2008;204(6):291.

25. Braun V, Clarke V. Using thematic analysis in psychology. Qual Res Psychol. 2006;3(2):77-101.

26. Creswell JW, Miller DL. Determining validity in qualitative inquiry. Theory Pract. 2000:39(3):124-30

27. Tong A, Sainsbury P, Craig J. Consolidated criteria for reporting qualitative research (COREQ): a 32-item checklist for interviews and focus groups. International J Qual Health Care. 2007;19(6):349-57.

28. Middleton A, Morley Kl, Bragin E, Firth HV, Hurles ME, Wright CF, et al. Attitudes of nearly 7000 health professionals, genomic researchers and publics toward the return of incidental results from sequencing research. Eur J Hum Genet. 2016;24(1):21-9.

29. Klitzman R, Appelbaum PS, Fyer A, Martinez J, Buquez B, Wynn J, et al. Researchers' views on return of incidental genomic research results: qualitative and quantitative findings. Genet Med. 2013;15(11):888-95.

30. Brandt DS, Shinkunas L, Hillis SL, Daack-Hirsch SE, Driessnack M, Downing $\mathrm{NR}$, et al. A closer look at the recommended criteria for disclosing genetic results: perspectives of medical genetic specialists, genomic researchers, and institutional review board chairs. J Genet Couns. 2013;22(4):544-53.

31. Berg JS, Amendola LM, Eng C, Van Allen E, Gray SW, Wagle N, et al. Processes and preliminary outputs for identification of actionable genes as 
incidental findings in genomic sequence data in the clinical sequencing exploratory research consortium. Genet Med. 2013;15(11):860-7.

32. Wynn J, Lewis K, Amendola LM, Bernhardt BA, Biswas S, Joshi M, et al. Clinical providers' experiences with returning results from genomic sequencing: an interview study. BMC Med Genet. 2018;11:13.

33. Roche MI, Berg JS. Incidental findings with genomic testing: implications for genetic counseling practice. Curr Genet Med Rep. 2015;3(4):166-76.

34. Wicklund CAL, Duquette DA, Swanson AL. Clinical genetic counselors: an asset in the era of precision medicine. Am J Med Genet C. 2018;178(1):63-7.

35. Tomlinson AN, Skinner D, Perry DL, Scollon SR, Roche MI, Bernhardt BA. "Not tied up neatly with a bow": professionals' challenging cases in informed consent for genomic sequencing. J Genet Couns. 2016;25(1):62-72.

36. Fiallos K, Applegate C, Mathews DJ, Bollinger J, Bergner AL, James CA. Choices for return of primary and secondary genomic research results of 790 members of families with Mendelian disease. Eur J Hum Genet. 2017; 25(5):530-7.

37. Smith $L A$, Douglas J, Braxton $A A$, Kramer K. Reporting incidental findings in clinical whole exome sequencing: incorporation of the 2013 ACMG recommendations into current practices of genetic counseling. J Genet Couns. 2015;24(4):654-62.

38. McConkie-Rosell A, Spiridigliozzi GA, Melvin E, Dawson DV, Lachiewicz AM. Living with genetic risk: Effect on adolescent self-concept. Am J Med Genet C. 2008;148c(1):56-69.

39. McConkie-Rosell A, DeVellis BM. Threat to parental role: a possible mechanism of altered self-concept related to carrier knowledge. J Genet Couns. 2000;9(4):285-302.

40. Abrams L, Cronister A, Brown WT, Tassone F, Sherman SL, Finucane B, et al. Newborn, carrier, and early childhood screening recommendations for fragile X. Pediatrics. 2012;130(6):1126-35.

41. Kohler JN, Turbitt E, Biesecker BB. Personal utility in genomic testing: a systematic literature review. Eur J Hum Genet. 2017;25(6):662-8.

42. Bunnik EM, Janssens A, Schermer MHN. Personal utility in genomic testing: is there such a thing? J Med Ethics. 2015;41(4):322-6.

43. Saelaert M, Mertes H, De Baere E, Devisch I. Incidental or secondary findings: an integrative and patient-inclusive approach to the current debate. Eur J Hum Genet. 2018;26(10):1424-31.

44. Delanne J, Nambot S, Chassagne A, Putois O, Pelissier A, Peyron C, et al. Secondary findings from whole-exome/genome sequencing evaluating stakeholder perspectives. A review of the literature. Eur J Med Genet. 2018;62(6):103529.

\section{Publisher's Note}

Springer Nature remains neutral with regard to jurisdictional claims in published maps and institutional affiliations.

Ready to submit your research? Choose BMC and benefit from:

- fast, convenient online submission

- thorough peer review by experienced researchers in your field

- rapid publication on acceptance

- support for research data, including large and complex data types

- gold Open Access which fosters wider collaboration and increased citations

- maximum visibility for your research: over $100 \mathrm{M}$ website views per year

At $\mathrm{BMC}$, research is always in progress.

Learn more biomedcentral.com/submissions 